\title{
Improved Properties of Ge MOS Capacitors with HfTiON or HfTiO Gate Dielectric by using Wet-NO Ge-Surface Pretreatment
}

\author{
C.X. Li ${ }^{1}$, X. Zou ${ }^{2,3}$, J.P. Xu ${ }^{2}$ and P.T. Lai ${ }^{1}$ \\ 1 Department of Electrical \& Electronic Engineering, the University of Hong Kong, \\ Pokfulam Road, Hong Kong \\ 2 Department of Electronic Science \& Technology, Huazhong University of Science and Technology, \\ Wuhan, 430074, P. R. China \\ 3 School of Electromachine \& Architecture Engineering, Jianghan University, \\ Wuhan, 430056, P. R. China
}

\begin{abstract}
HfTiO/GeO $\mathrm{G}_{\mathrm{y}}$ and $\mathrm{HfTiON} / \mathrm{GeO}_{\mathrm{x}} \mathrm{N}_{\mathrm{y}}$ stack gate dielectrics are prepared by using wet-NO or wet- $\mathrm{N}_{2} \mathrm{O}$ pretreatment on Ge substrate. Experimental results show that the wet NO pretreatment can lead to excellent interface properties, gate leakage properties and device reliability, especially for the $\mathrm{HfTiON} / \mathrm{GeO}_{\mathrm{x}} \mathrm{N}_{\mathrm{y}}$ dielectric. The involved mechanisms lie in the roles of $N$ in blocking oxygen diffusion and $G e$ out-diffusion and suitable $\mathrm{N}$ incorporation in the $\mathrm{GeO}_{\mathrm{x}} \mathrm{N}_{\mathrm{y}}$ interlayer, which effectively suppress further growth of $\mathrm{GeO}_{\mathrm{x}} \mathrm{N}_{\mathrm{y}}$ interlayer and the growth of unstable $\mathrm{GeO}_{\mathrm{x}}$ during subsequent processing.
\end{abstract}

\section{INTRODUCTION}

For the past several decades, improved performance of silicon-based metal-oxidesemiconductor field-effect transistors (MOSFETs) has been mainly accomplished by reducing the device dimensions to achieve higher packing density and less power consumption. However, saturation of drain current and unacceptable high gate leakage upon dimension shrinkage limit the prospect for future scaling. To overcome this problem, germanium channel material can be used to enhance the drive current due to its high carrier mobility, and also high-k (relative permittivity) gate dielectric with larger thickness can be utilized to decrease the gate leakage. At present, excellent reliability and high transistor performance have been demonstrated by depositing high-k gate dielectrics on Ge substrate, such as $\mathrm{ZrO}_{2}$ [1], $\mathrm{HfO}_{2}$ [2], GeON [3] and $\mathrm{Ge}_{3} \mathrm{~N}_{4}$ [4]. A problem is that a thermodynamically unstable and low-permittivity $\mathrm{GeO}_{\mathrm{x}}$ interlayer is inevitably grown during the formation of the high-k gate dielectric, thus increasing the equivalent oxide thickness and gate leakage current. Therefore, methods were proposed to fabricate high-quality gate dielectrics with largely suppressed growth of $\mathrm{GeO}_{\mathrm{x}}$, e.g. $\mathrm{NH}_{3}$ surface nitridation [5-6], $\mathrm{SiH}_{4}$ surface passivation [7, 8], and wet-NO thermal oxidation [9].

It is well known that $\mathrm{Ti}$ oxide has higher $\mathrm{k}$ value than $\mathrm{Hf}$ oxide [10]. So, addition of $\mathrm{Ti}$ in $\mathrm{Hf}$ oxide can form HfTi-based oxide with higher $\mathrm{k}$ value. In this work, $\mathrm{Al} / \mathrm{HfTiON} / \mathrm{Ge}$ and $\mathrm{Al} / \mathrm{HfTiO} / \mathrm{Ge}$ MOS devices are investigated and a wet $\mathrm{NO}$ Ge-surface pretreatment before the high-k dielectric deposition is employed to obtain good interface property. Due to formation of a $\mathrm{GeO}_{\mathrm{x}} \mathrm{N}_{\mathrm{y}}$ interlayer by the NO surface pretreatment, diffusions of $\mathrm{O}, \mathrm{Ti}$ and $\mathrm{Hf}$ to the substrate and out-diffusion of Ge can be effectively blocked, thus resulting in less oxide charges and interface states. Also, the post-deposition annealing (PDA) is performed in a wet- $\mathrm{N}_{2}$ ambient to further suppress the $\mathrm{GeO}_{\mathrm{x}}$ growth on the Ge surface [9]. Experimental results show that excellent device performance, including low gate leakage current and interface-state density, can be obtained by the proposed method.

\section{DEVICE STRUCTURE}

The Ge substrate was (100) Sb-doped n-type wafers from Umicore Ltd. with a resistivity of 0.040 $\sim 0.047 \Omega \mathrm{cm}$. The wafers were cleaned with acetone, trichloroethylene, toluene and ethanol, and lastly with de-ionized water rinsing followed by 30 -s diluted HF (1:50) dipping for several cycles to remove the native oxide $\left(\mathrm{GeO}_{\mathrm{x}}\right)$. After drying by $\mathrm{N}_{2}$, a surface pretreatment was immediately carried out in wet $\mathrm{N}_{2} \mathrm{O}$ or wet $\mathrm{NO}$ for $60 \mathrm{~s}$ at $500{ }^{\circ} \mathrm{C}$ (denoted as the $\mathrm{N}-\mathrm{N} 2 \mathrm{O}$ and $\mathrm{N}-\mathrm{NO}$ samples respectively) to form a $\mathrm{Ge}$ oxynitride passivation layer. No surface pretreatment was done for the control sample (denoted as the N-N2 sample). The wet ambient for suppressing the growth of unstable $\mathrm{GeO}_{\mathrm{x}}$ was realized by bubbling the pure gas through de-ionized water at $95{ }^{\circ} \mathrm{C}$. A HfTiN film was subsequently deposited by reactive co-sputtering of $\mathrm{Hf}$ and $\mathrm{Ti}$ in an $\mathrm{Ar}+\mathrm{N}_{2}$ ambient at room temperature, followed by an annealing in wet $\mathrm{N}_{2}$ ambient at $500{ }^{\circ} \mathrm{C}$ for $5 \mathrm{~min}$ to convert HfTiN into high-k HfTiON. For the purpose of comparison, another group of samples with HfTiO as high-k layer were prepared in an $\mathrm{Ar}+$ $\mathrm{O}_{2}$ ambient on the passivated and non-passivated $\mathrm{Ge}$ surface, with the same annealing conditions, (accordingly denoted as $\mathrm{O}-\mathrm{N} 2 \mathrm{O}, \mathrm{O}-\mathrm{NO}$ and $\mathrm{O}-\mathrm{N} 2$ respectively). Finally, $\mathrm{Al}$ was thermally evaporated 
and patterned as gate electrode with an area of $7.85 \times 10^{-5} \mathrm{~cm}^{2}$, and followed by forming-gas annealing at $300^{\circ} \mathrm{C}$ for $20 \mathrm{~min}$ to achieve better electrical contacts.

High-frequency

(HF, $\quad 1-\mathrm{MHz})$ capacitance-voltage $(C-V)$ characteristics were measured at room temperature using HP4284A precision LCR meter. Gate leakage current was measured by HP 4156A precision semiconductor parameter analyzer. Physical thickness of the gate dielectrics was determined by a VASE Series Ellipsometer of J. A. Wollam Co. High-field stress (at $10 \mathrm{MV} / \mathrm{cm}$ ), with the capacitors biased in accumulation by HP 4156A precision semiconductor parameter analyzer, was used to examine device reliability in terms of gate-leakage increase and flatband-voltage shift. All electrical measurements were carried out under a light-tight and electrically-shielded condition.

\section{RESULTS and DISCUSSION}

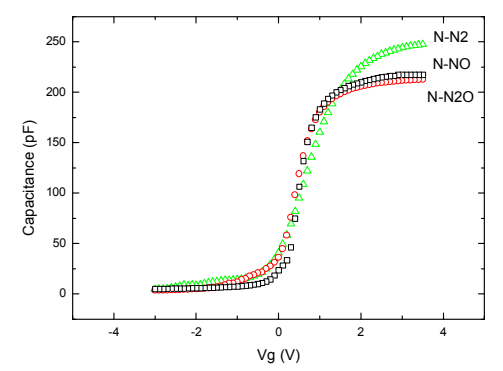

1(a)

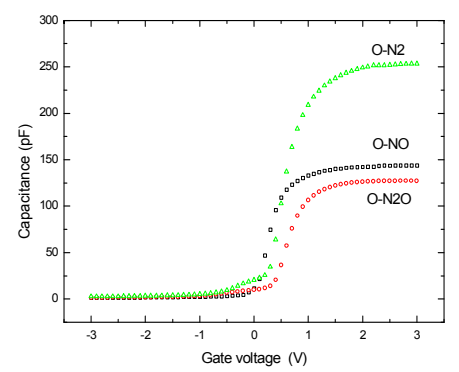

$1(\mathrm{~b})$

Fig.1 High-frequency (1-MHz) C-V curves for (a) HfTiON gate-dielectric samples; (b) HfTiO gate-dielectric samples.

Table 1 Electrical parameters extracted from $1-\mathrm{MHz}$ $\mathrm{C}-\mathrm{V}$ curves for the samples.

\begin{tabular}{|lllllll|}
\hline Sample & $\begin{array}{l}t_{o x} \\
(\mathrm{~nm})\end{array}$ & $\begin{array}{l}\mathrm{C}_{\mathrm{ox}} \\
(\mathrm{pF})\end{array}$ & $\begin{array}{l}\mathrm{CET} \\
(\mathrm{nm})\end{array}$ & $\begin{array}{l}V_{\mathrm{fb}} \\
(\mathrm{V})\end{array}$ & $\begin{array}{l}D_{\text {it }} \\
\left(\mathrm{cm}^{-2} \mathrm{eV}^{-1}\right)\end{array}$ & $k$ \\
\hline N-N2 & 6.07 & 249 & 1.09 & 0.21 & $8.1 \times 10^{11}$ & 24.5 \\
\hline N-NO & 7.20 & 217 & 1.24 & 0.34 & $1.3 \times 10^{11}$ & 23.4 \\
\hline N-N2O & 7.24 & 213 & 1.28 & 0.31 & $1.6 \times 10^{11}$ & 21.6 \\
\hline O-N2 & 7.18 & 253 & 1.08 & 0.29 & $1.3 \times 10^{12}$ & 25.9 \\
\hline O-NO & 8.57 & 145 & 1.88 & 0.18 & $2.1 \times 10^{11}$ & 17.8 \\
\hline O-N2O & 8.98 & 127 & 2.15 & 0.49 & $6.9 \times 10^{11}$ & 16.3 \\
\hline
\end{tabular}

Typical HF $C-V$ curves of the samples are depicted in Fig. 1. The values of gate-dielectric capacitance $\left(C_{o x}\right)$, capacitance equivalent thickness
(CET) and flat-band voltage $\left(V_{f b}\right)$ extracted from the $1-\mathrm{MHz} \mathrm{C}-\mathrm{V}$ curve are listed in Table $1 . C_{o x}$ is the accumulation capacitance; $\mathrm{CET}=A \varepsilon_{\mathrm{SiO} 2} \varepsilon_{0} / C_{\mathrm{ox}}$, where $A$ is the area of capacitor; $\varepsilon_{\mathrm{SiO} 2}$ and $\varepsilon_{0}$ are the permittivity of $\mathrm{SiO}_{2}$ and vacuum respectively. Interface-state density at midgap $\left(D_{i t}\right)$ is also extracted from the $1-\mathrm{MHz} C-V$ curve using the Terman's method for comparison purpose [11]. A large drop in $C_{o x}$ is observed for the O-N2O and O-NO samples relative to their control sample (O-N2), indicating a large $C E T$, as listed in Table 1. Fig. 2 shows the TEM images of the O-N2 and N-N2 control samples. It can be seen that no visible interlayer between $\mathrm{Ge}$ and $\mathrm{HfTiO}$ or HfTiON dielectric is observed in the two control samples due to the wet annealing ambient [9]. The physical thickness $\left(t_{o x}\right)$ of gate dielectric for the control sample is $\sim 7.2 \mathrm{~nm}$ and $\sim 6.0 \mathrm{~nm}$ from the TEM images, which is consistent with the measured result by ellipsometry $(7.18 \mathrm{~nm}$ and $6.07 \mathrm{~nm})$. So, the $t_{o x}$ 's of other samples are determined by ellipsometry and listed in Table 1. The interlayer thickness between Ge and HfTiO or HfTiON can be calculated to be $1.39 \mathrm{~nm}$ and $1.80 \mathrm{~nm}$ for the O-NO and O-N2O samples, and $\sim 1.13 \mathrm{~nm}$ and $1.17 \mathrm{~nm}$ for the N-NO and $\mathrm{N}-\mathrm{N} 2 \mathrm{O}$ samples respectively, due to the same deposition conditions of HfTiO or HfTiON as the $\mathrm{O}-\mathrm{N} 2$ or N-N2 control samples. Obviously, the large CET's for the O-NO and O-N2O samples are ascribed to enhanced growth of $\mathrm{GeO}_{x} \mathrm{~N}_{y}$ interlayer with more $\mathrm{O}$ content during subsequent annealing due to existence of HfTiO dielectric. The largest interlayer thickness for the O-N2O sample results mainly from enhanced oxidation during $\mathrm{N}_{2} \mathrm{O}$ pretreatment. For the N-NO and N-N2O samples with HfTiON dielectric, further growth of the $\mathrm{GeO}_{\mathrm{x}} \mathrm{N}_{\mathrm{y}}$ interlayer is effectively suppressed by the oxygen-blocking role of the nitrogen in the dielectric, leading to only a small CET increase as compared with their control sample N-N2. The smaller CET for the O-NO sample than the O-N2O sample is attributed to the self-limiting nature of NO oxidation and better nitridation effect of $\mathrm{NO}$ gas (more nitrogen incorporation) [12].

The lowest $D_{i t}$ 's are found for the two NO-passivated samples $\left(1.3 \times 10^{11} \mathrm{eV}^{-1} \mathrm{~cm}^{-2}\right.$ and $2.1 \times 10^{11} \mathrm{eV}^{-1} \mathrm{~cm}^{-2}$ ) due to the growth of $\mathrm{GeO}_{\mathrm{x}} \mathrm{N}_{\mathrm{y}}$ interlayer with suitable $\mathrm{N}$ content, which effectively blocks $\mathrm{O}$ diffusion to the substrate and out-diffusing of $\mathrm{Ge}$, thus resulting in less structural defects near the interface. The larger $D_{i t}$ for the O-NO sample than the N-NO sample is probably due to more $\mathrm{O}$ content in $\mathrm{GeO}_{\mathrm{x}} \mathrm{N}_{\mathrm{y}}$ for the former than the latter, as mentioned above. Similarly, higher $D_{\text {it }}$ for the $\mathrm{N}_{2} \mathrm{O}$-passivated samples than the NO-passivated sample is also associated with out-diffusion of some Ge's due to lower $\mathrm{N}$ content in the interlayer and thus weakening its barrier role, especially for the O-N2O sample. The high interface-state density for the two control samples probably results from significant $\mathrm{Ge}$ out-diffusion which induces a large amount of defects through direct reaction of Ge with HfTiO or HfTiON near the interface [13] due to no oxynitride 
interlayer. This problem is alleviated for the N-N2 sample due to $\mathrm{N}$ incorporation in HfTiN depostion.
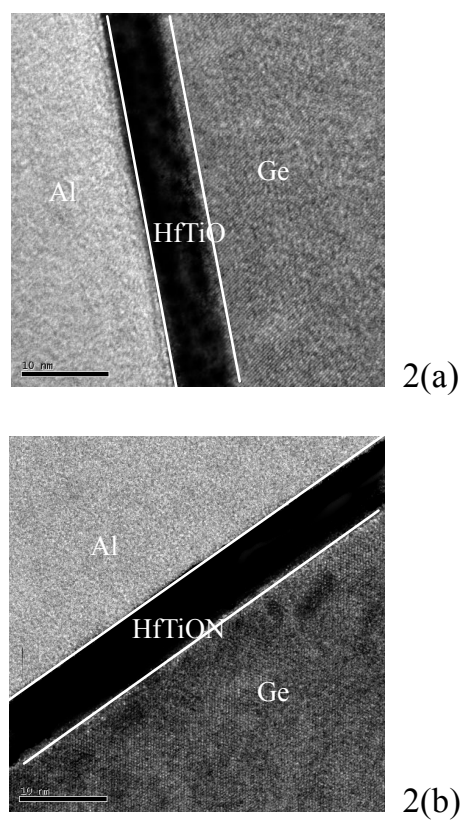

Fig.2 TEM image of (a) Al/HfTiO/Ge control capacitor; (b) Al/HfTiON/Ge control capacitor.

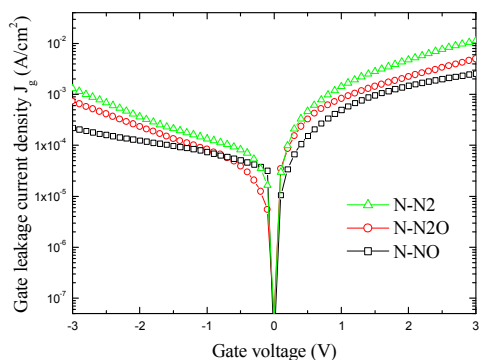

3(a)

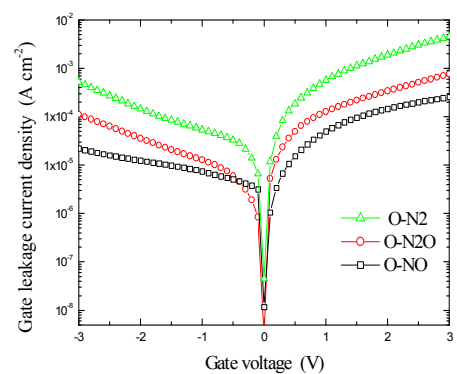

3(b)

Fig.3 Gate leakage current vs. gate voltage for (a) HfTiON gate-dielectric samples; (b) HfTiO gate-dielectric samples.

The gate-leakage properties of the samples are measured in Fig.3. The gate leakage of the HfTiO gate dielectrics is smaller than that of the HfTiON gate dielectrics due to larger physical thickness. For the two groups of gate dielectrics, the NO sample exhibits the lowest gate leakage current, e.g. $4.9 \times 10^{-5}$ $\mathrm{A} / \mathrm{cm}^{2}$ and $8.0 \times 10^{-4} \mathrm{~A} / \mathrm{cm}^{2}$ at $V_{g}=1 \mathrm{~V}$ (accumulation) for the O-NO and N-NO samples respectively, because of its superior interface property and good insulating property of the $\mathrm{HfTiO} / \mathrm{GeO}_{\mathrm{x}} \mathrm{N}_{\mathrm{y}}$ or
HfTiON/ $\mathrm{GeO}_{\mathrm{x}} \mathrm{N}_{\mathrm{y}}$ gate dielectric. The higher gate leakage current of the $\mathrm{N} 2 \mathrm{O}$ sample than that of the NO sample lies in its larger $D_{\text {it }}$. The largest leakage current of the control samples should be attributed to their smallest dielectric thickness and largest $\mathrm{D}_{\mathrm{it}}$.

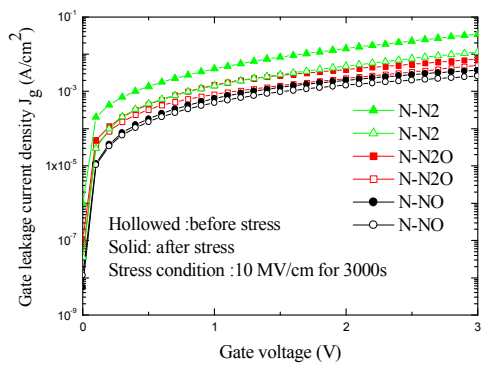

4(a)

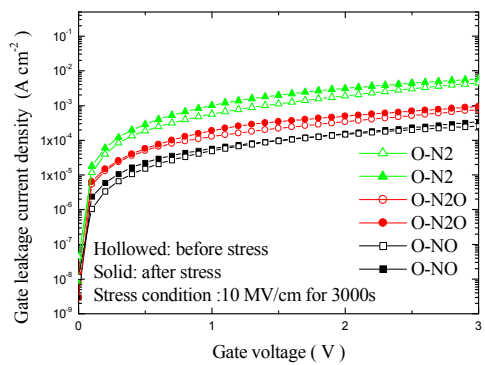

4(b)

Fig. 4 Gate leakage current of HfTiO and HfTiON gate-dielectric samples before and after a high-field stress (10 MV/cm for $3000 \mathrm{~s})$.

Table 2 Changes of $D_{i t}, V_{f b}$ and $J_{g}$ of HfTiON and HfTiO gate-dielectric MOS capacitors after stress.

\begin{tabular}{|c|c|c|c|}
\hline Sample & $\begin{array}{c}\Delta J_{g} \underset{\left(\mathrm{A} / \mathrm{cm}^{2}\right)}{\left(\mathrm{V}_{\mathrm{g}}=1 \mathrm{~V}\right.} \\
\end{array}$ & $\begin{array}{l}\Delta \Delta V_{f b} \\
(\mathrm{~V})\end{array}$ & $\begin{array}{c}\Delta D_{i t} \\
\left(\mathrm{~cm}^{-2} \mathrm{eV}^{-1}\right)\end{array}$ \\
\hline $\mathrm{N}-\mathrm{N} 2$ & $2.6 \times 10^{-3}$ & 0.31 & $5.0 \times 10^{11}$ \\
\hline $\mathrm{N}-\mathrm{NO}$ & $1.4 \times 10^{-4}$ & 0.09 & $0.9 \times 10^{11}$ \\
\hline $\mathrm{N}-\mathrm{N} 2 \mathrm{O}$ & $6.6 \times 10^{-4}$ & 0.16 & $1.9 \times 10^{11}$ \\
\hline O-N2 & $4.5 \times 10^{-4}$ & 0.42 & $6.3 \times 10^{11}$ \\
\hline $\mathrm{O}-\mathrm{NO}$ & $7.7 \times 10^{-6}$ & 0.13 & $1.7 \times 10^{11}$ \\
\hline $\mathrm{O}-\mathrm{N} 2 \mathrm{O}$ & $7.8 \times 10^{-5}$ & 0.25 & $3.4 \times 10^{11}$ \\
\hline
\end{tabular}

For the HfTiON and HfTiO gate-dielectric samples, a high-field stressing experiment (10 $\mathrm{MV} / \mathrm{cm}$ for $3000 \mathrm{~s}$ ) is done to evaluate the device reliability. Fig. 4 shows the leakage current in accumulation region before and after stressing. The stress-induced changes of $D_{i t}, J_{g}$, and $V_{f b}$ (flatband voltage) for the samples are listed in Table 2. It is clearly shown that the NO sample has the smallest increases of $D_{i t}, V_{f b}$ and $J_{g}$ due to more nitrogen incorporation, and thus better interlayer quality. Compared with the $\mathrm{N} 2 \mathrm{O}$ sample, the NO sample with more nitrogen incorporation in the passivation layer has more strong Ge-N bonds $\left(\mathrm{E}_{\mathrm{Ge}-\mathrm{N}}=275\right.$ $\mathrm{kJ} / \mathrm{mol}$ ) (instead of unstable $\mathrm{Ge}-\mathrm{O}$ bonds), which enhance the resistance of the dielectric against the 
generation of interface states during stress, thus suppressing the increases of $D_{i t}, V_{f b}$ and $J_{g}$.

The $k$ of the gate stack dielectric, as calculated by $\varepsilon_{\mathrm{SiO} 2} \times\left(t_{o x} / C E T\right)$, is listed in Table 1 too. It should be noted that $k$ is an equivalent $k$-value of the dielectric and interlayer. Based on the formula of $k=$ $\varepsilon_{\mathrm{SiO} 2} \times t_{\mathrm{ox}} / C E T=t_{\mathrm{ox}} /\left(t_{\mathrm{IL}} / \varepsilon_{\mathrm{IL}}+t_{\mathrm{die}} / \varepsilon_{\mathrm{die}}\right)$, where $t_{\mathrm{IL}}$ and $\varepsilon_{\mathrm{IL}}$, and $t_{\text {die }}$ and $\varepsilon_{\text {die }}$ are physical thickness and permittivity of the interlayer and high-k dielectric layer respectively, the relative permittivity of the $\mathrm{GeO}_{\mathrm{x}} \mathrm{N}_{\mathrm{y}}$ interlayer can be calculated to be 6.81 and 6.56 for the O-NO and O-N2O samples respectively by using $\varepsilon_{\text {die }}=25.9$ for the HfTiO dielectric layer. The $\varepsilon_{\mathrm{IL}}$ of the NO sample is larger than that of the $\mathrm{N} 2 \mathrm{O}$ sample due to higher $\mathrm{N}$ content.

\section{CONCLUSION}

$\mathrm{HfTiON} / \mathrm{GeO}_{\mathrm{x}} \mathrm{N}_{\mathrm{y}}$ and $\mathrm{HfTiO} / \mathrm{GeO}_{\mathrm{x}} \mathrm{N}_{\mathrm{y}}$ stack gate dielectrics have been prepared on $\mathrm{Ge}$ substrate by Ge-surface pretreatment in wet $\mathrm{NO}$ or $\mathrm{N}_{2} \mathrm{O}$ ambient. Experimental results indicate that the wet-NO surface nitridation can effectively decrease the interface-state density, and thus gate leakage current. The involved mechanisms lie in the formation of a $\mathrm{GeO}_{\mathrm{x}} \mathrm{N}_{\mathrm{y}}$ interlayer, good $\mathrm{GeO}_{\mathrm{x}} \mathrm{N}_{\mathrm{y}} / \mathrm{Ge}$ interface property and insulating property of the $\mathrm{HfTiON} / \mathrm{GeO}_{\mathrm{x}} \mathrm{N}_{\mathrm{y}}$ or $\mathrm{HfTiO} / \mathrm{GeO}_{\mathrm{x}} \mathrm{N}_{\mathrm{y}}$ dielectric. Furthermore, it is found that the $\mathrm{HfTiON} / \mathrm{GeO}_{\mathrm{x}} \mathrm{N}_{\mathrm{y}}$ dielectric has better interface properties and higher equivalent $k$ value than the $\mathrm{HfTiO} / \mathrm{GeO}_{\mathrm{x}} \mathrm{N}_{\mathrm{y}}$ dielectric due to good O-blocking role of nitrogen and more $\mathrm{N}$ incorporation in the $\mathrm{GeO}_{\mathrm{x}} \mathrm{N}_{\mathrm{y}}$ interlayer, thus suppressing the growth of the interlayer. In addition, high-field stressing shows that the $\mathrm{HfTiON} / \mathrm{GeO}_{\mathrm{x}} \mathrm{N}_{\mathrm{y}}$ dielectric with wet-NO surface pretreatment exhibits excellent device reliability (smaller increases of $D_{i t}$, $V_{f b}$ and $J_{g}$ after electrical stress) through the formation of more strong Ge-N bonds. Therefore, the wet-NO surface pretreatment plus wet- $\mathrm{N}_{2}$ post-deposition anneal should be a promising method for fabricating high- $k$ HfTiON $/ \mathrm{GeO}_{\mathrm{x}} \mathrm{N}_{\mathrm{y}}$ gate-dielectric Ge MOSFETs with excellent interface and gate-leakage properties, and device reliability.

\section{ACKNOWLEDGEMENT}

The work is financially supported by the RGC of HKSAR, China (Project No. HKU 713308E), the HKU Small Project Funding (Project No. 200707176147), and the National Natural Science Foundation of China (Grant no. 60776016).

\section{REFERENCES}

[1] S. K. Mandal, S. Charkraborty, C. K. Maiti, "Ge-channel p-MOSFETs with $\mathrm{ZrO}_{2}$ gate dielectric," Microelectronic Engineering, vol.81, pp.206-211, 2005.

[2] A. Dimoulas, G. Mavrou, G.Velliantis, E. Evangelou, N.Boukos., M. Houssa and M.
Caymax, " $\mathrm{HfO}_{2}$ high- $\kappa$ gate dielectrics on $\mathrm{Ge}(100)$ by atomic oxygen beam deposition," Appl. Phys. Lett., vol.86, pp.032908,2005.

[3] C. O. Chui, F. Ito, K. C. Saraswat, "Scalability and electrical properties of Germanium oxynitride MOS dielectric," IEEE Electron Device Letters, vol.25, no.9, pp.613-615, 2004.

[4] T. Maeda, T. Yasuda, M. Nishizawa, N. Miyata, Y. Morita, S. Takagi, "Ge metal-insulator-semiconductor structures with $\mathrm{Ge}_{3} \mathrm{~N}_{4}$ dielectrics by direct nitridation of $\mathrm{Ge}$ surfaces," Appl. Phys. Lett., vol.85, no. 15,pp.3181-3183,2004.

[5] S. Van Elshocht, B. Brijs, M. Caymax, T. Conard, T. Chiarella, S. De Gendt, B. De Jager, S. Kubicek, M. Meuris, B. Onsia, O. Richard, I. Teerlinck, J. Van Steenbergen, C. Zhao, and M. Heyns, "Deposition of HfO2 on germanium and the impact of surface pretreatments," Appl. Phys. Lett., vol. 85, no. 17, pp. 3824-3826, 2004.

[6] C. O. Chui, H. Kim, P. C. McIntyre, and K. C. Saraswat, "Atomic layer deposition of high- $\kappa$ dielectric for germanium MOS applications-substrate surface preparation," IEEE electron Device Lett., vol. 25, no.5, pp.274-276, 2004.

[7] W. P. Bai, N. Lu, and D. -L. Kwong, "Si interlayer passivation on germanium MOS capacitors with high-k dielectric and metal gate," IEEE Electron Deavice Lett., vol. 26, no. 6, pp. 378-380, 2005.

[8] N. Wu, Q. Zhang, C. Zhu, D. S. H. Chan, A. du, N. Balasubramanian, M. F. Li, A. Chin, J. K. O. Sin, D.-L.Kong, "A TaN-HfO $2-$ Ge pMOSFET with novel $\mathrm{SiH}_{4}$ surface passivation," IEEE Electron Device Lett., vol. 25 no. 9, pp. 631-633, 2004.

[9] J. P. Xu, P. T. Lai, C. X. Li, X. Zou, C. L. Chan, "Improved electrical properties of Germanium MOS capacitor with gate dielectric grown in wet-NO ambient," IEEE electron Device Lett., vol. 27, no.6, pp.439-441, Jun.2006.

[10] J. Mcpherson, J. Kim, A. Shanware, H. Mogual, and J. Rodriguez, IEEE IEDM. 633 (2002).

[11] L. M. Terman, "An investigation of surface states at a silicon/silicon oxide interface employing metal-oxide-silicon diodes," Solid-State Electronics, vol. 5, pp. 285-299, 1962.

[12] M.Bhat, J. Kim, J. Yan, G. W. Yoon, L. K. Han and D. L. Kwong, "MOS characteristics of ultrathin NO-Grown oxynitrides," IEEE Electron Device Lett., vol.15, no.10, pp. 421-423,1994.

[13] N. Lu, W. Bai, A. Ramirez, C. Mouli, A. Ritenour, M. L. Lee, D. Antoniadis, D.L.Kwong, "Ge diffusion in Ge metal oxide semiconductor with chemical vapor deposition $\mathrm{HfO}_{2}$ dielectric," Appl. Phys. Lett., Vol. 87, pp. 051922, 2005. 